\title{
Teacher perceptions of A-level music: tension, dilemmas and decline
}

\author{
Adam Whittaker \\ Royal Birmingham Conservatoire, 200 Jennens Road, Birmingham, B4 7XR, UK \\ Corresponding author. Email: adam.whittaker@bcu.ac.uk
}

\begin{abstract}
A-level music, a qualification taken most often in English and Welsh school contexts around the age of 18, has been a long-standing feature of the musical training of many musicians. Historically bound up with Western European Art Music, the qualification has somewhat broadened its horizons in recent times, though with mixed success in opening up new ways of thinking about music. Recent research has highlighted the seemingly precarious nature of A-level music in many English schools. The reasons for this picture of decline are highly complex and difficult to disentangle, and are part of a much broader diminishing of creative subjects in the school curriculum. Decreasing numbers of A-level music entries run somewhat counter to popular policy discourse, which celebrates flagship announcements of $£ 79$ million given to Music Education Hubs in 2019-2020, and 2018 survey results that reported more than 700,000 children learning to play a musical instrument through music hub provision. However, behind these headlines, although there are many children having the opportunity to learn a musical instrument, few continue through to A-level and beyond. Despite its declining numbers, A-level music is recognised as a valuable qualification amongst music teachers, offering something distinct from graded music examinations and other Level 3 musical qualifications. This article presents the results of a recent nationwide survey of A-level music teachers to offer an insight into teacher perceptions of current A-level music specifications, the extent to which it prepares students for entry into higher musical education, and its appropriateness for aspiring young musicians.
\end{abstract}

Keywords: A-level music; 16-18 music; music qualifications; Key Stage 5 music; music examinations

A-level music, a qualification taken in English and Welsh school contexts around the age of 18, has been a long-standing feature of the musical training of many musicians, often taken before continuing on to higher musical study at a university or music college. Historically bound up with Western European Art Music, the qualification has somewhat broadened its horizons in recent times, including elements from musical traditions outside of Western European Art Music. Taken during Key Stage 5 (the final 2 years of school, aged 16-18), A-level music focuses upon three principal areas of activity: performance, composition and listening/music history. The combination of these three elements within a single qualification renders A-level as a distinctly different proposition from other music qualifications such as graded music examinations. By their very nature, these focus predominantly on skills in instrumental and vocal performance, and/or theory, and do not include opportunities for extended discussions of musical contexts and analytical study of a body of set works. Graded music examinations are also often genre bound, focusing on specific categories of musical style (jazz, classical, traditional, etc.) reflecting assessments of specialist skills. A similar assessment might be made of equivalent Level 3 qualifications, such as BTEC, which tend to have a stronger focus towards performing skills, often in popular musical styles. 
Table 1. Assessment Objectives from Ofqual Guidance (Ofqual, 2015)

\begin{tabular}{|c|c|c|}
\hline & Objective & Weightage \\
\hline $\mathrm{AO1}$ & $\begin{array}{l}\text { Interpret musical ideas through performing, with technical and expressive } \\
\text { control and an understanding of style and context. }\end{array}$ & $25 \%-35 \%$ \\
\hline $\mathrm{AO} 2$ & Create and develop musical ideas with technical and expressive control and coherence. & $25 \%-35 \%$ \\
\hline $\mathrm{AO3}$ & Demonstrate and apply musical knowledge. & $10 \%$ \\
\hline $\mathrm{AO} 4$ & Use analytical and appraising skills to make evaluative and critical judgements about music. & $30 \%$ \\
\hline
\end{tabular}

A-level, in theory at least, addresses a broader range of musical skills within a single qualification. At present, there are four examination boards offering A-level music courses: AQA, Edexcel, OCR and Eduqas. Although each of these examination boards presents some slightly different approaches, they are all required to assess the following four assessment objectives and weight marks in particular skill areas, stipulated by Ofqual, the UK's qualifications regulator: these are outlined in Table 1.

To summarise these, AO1 relates to performing, AO2 to composition, AO4 deals with listening and appraising, and $\mathrm{AO} 3$ operates across different skill sets. Thus, three principal skill areas are weighted reasonably equally, though with the caveat that the precise allocations of marks in $\mathrm{AO} 1$ and $\mathrm{AO} 2$ are determined by examination boards themselves.

\section{Review of the literature and policy context}

Recent research has highlighted the seemingly precarious nature of A-level music in many English schools (see, e.g., Bath et al., 2020). The 'State of the Nation' report, published by the Incorporated Society of Musicians, drew attention to a significant decrease in the number of students being entered for A-level music, with entries falling by over 38\% between 2010 and 2018 (Daubney, Spruce, \& Annetts, 2019, p. 15). According to the Association of School and College Leaders (2018), music is the subject experiencing the fastest decline at A-level. These reductions are particularly pronounced in less affluent areas, with significant regional differences in the number of students being entered for A-level music (Whittaker et al., 2019). There is also evidence that the independent school sector (which is mostly fee-paying) accounts for a disproportionately high number of A-level music entries, and that the overall proportion of entries from the independent sector is growing; this means that entries from the state-funded school sector are falling. In 2018, independent schools accounted for $27.9 \%$ of A-level music entries, compared with $25.2 \%$ in 2014 (Whittaker et al. 2019, p. 14). Nationally, the independent school population accounts for just $8 \%$ of those attending school, meaning that entries from the independent sector are disproportionately high. Alongside these wider reductions in the number of entries, from 2010 to 2017, there was a $22.6 \%$ decrease in the number of secondary school music teachers working at Key Stage 5. Consequently, the number of hours of music taught in KS5 fell by $17.8 \%$ between 2010 and 2017 (Daubney, Spruce, \& Annetts, 2019, p. 11). All this presents a somewhat bleak picture.

The reasons for this picture of decline are highly complex and difficult to disentangle, and are part of a much broader diminishing of creative subjects in the school curriculum. Perhaps, the most significant educational policy to have bearing on this decline is the English Baccalaureate (EBacc) which, as reported in a recent BBC study, has led to a significant number of secondary schools cutting back creative arts provision (Jeffreys, 2018). The EBacc is a performativity tool against which school league table positions are judged. It measures school performance in a number of 'core subjects', prioritising maths, English and the sciences; arts subjects are not included (Cultural Learning Alliance, 2017). Savage and Barnard (2019) posit that the EBacc has 'skewed the school curriculum to such an extent that music is often marginalised at the expense of what 
some policymakers consider as more 'serious' or 'academic' subjects' (p. 7). There has been much consternation in the media about the impact of the EBacc on the arts in schools, including the high profile 'Bacc for the Future' campaign (Incorporated Society of Musicians, 2020). With music rarely featuring in Ofsted inspection visits and audits, school resources and energies are often put towards fulfilling the requirements of the EBacc accountability measure, which holds importance for league table placings and, importantly, access to further funding. Thus, creative subjects may become less of a priority, leading to them being 'squeezed out' of the curriculum. If these subjects are not present in the earlier parts of the curriculum, then what chance do they have for small examination groups at KS4 and KS5?

Corroborating evidence can be found in the rise in the number of music departments with up to one full-time equivalent member of staff. Daubney and Mackrill (2017) reported that 29\% of music departments across their sample were made up of a single member of staff who, in some cases, was not even employed on a full-time basis. Such reductions in staff time have wider implications for the cultural lives of schools, with reduced opportunities for teachers to run extracurricular activities that support a wider musical ecosystem within a school.

These statistics run counter to popular policy discourse, which celebrates flagship announcements of $£ 79$ million given to Music Education Hubs in 2019-2020, and 2018 survey results that reported more than 700,000 children learning to play a musical instrument each year through music hub provision (Fautley \& Whittaker, 2018). The reality of the picture behind these headlines is that although there are many children having the opportunity to learn a musical instrument, few continue through to A-level and beyond, contributing to something a 'gap' between socioeconomic groups in access to higher levels of musical education (Moore, 2014). Using Participation of Local Areas Ratings (henceforth, POLAR) data, the UK University Admissions Service (UCAS) showed that those accepted onto higher music courses come disproportionately from households who have had prior access to higher education or are located in more advantaged areas (Kernohan, 2020). Of the 3,590 acceptances in 2019, 32\% came from POLAR 5 postcodes (those with highest proportions of entry to HE), compared with just $11.84 \%$ from POLAR 1 postcodes (those with lowest proportions of entry to HE) (Kernohan, 2020). According to the National Pupil Database, in 2018/19, nine local authorities saw fewer than five A-level music entries across their area (Department for Education, 2019). For many of these, such low numbers of A-level music entries represent vanishingly small proportions of their local authority population. Both of these points have implications for the number of students continuing through to study music in higher education, and point to a looming issue with the 'pipeline' for the next generation of musicians (Whittaker et al., 2019).

All this points towards the place of A-level music as a relatively exclusive qualification in the British educational landscape, and one whose relative exclusivity is increasing year by year. Given the different operationalisation of BTECs and equivalent musical Level 3 qualifications, and their focus towards practical skills offering a different kind of learning experience, the present study does not investigate these. Instead, the present study sought to explore teacher perceptions of the A-level music qualification in its present form, the aspects of the qualifications that were most challenging, and whether it supported transitions into higher musical education.

\section{Methodology}

This paper draws on the results of an online survey conducted in autumn 2018, whereby teachers were asked to share their experiences of A-level music, the areas that their students find most challenging, and the extent to which the qualification serves as a preparation for musical study in higher education. The online survey was shared via special interest groups for music teachers and professional network associations to seek a broad range of respondents from across the country working in different educational contexts. 
Surveying has a long history within educational research (Cresswell, 2009) and affords the opportunity to both take an important snapshot of the range of experiences from a particular population and see the 'bigger picture' (Denscombe, 2010, p. 141). The survey used mostly closed questions to ascertain the key areas of interest amongst teachers, and open questions to capture more fully the 'authenticity, richness, depth of response' of respondent perspectives (Cohen, Manion, \& Morrison, 2018, p. 475), mitigating potential bias towards the researcher's aims. Throughout the survey, respondents were given an 'other' option, avoiding unnecessarily lengthy lists of options (Denscombe, 2014, p. 176), and 'enabling respondents to reply in their own terms' (Cohen, Manion, \& Morrison, 2018, p. 475). This approach ensured that the survey supported the collection of rich data, rather than simply a high volume of data alone (Newby, 2010), and supported analysis across the dataset and within individual responses. The survey was designed using the Online Surveys tool (formerly Bristol Online Surveys) which is compatible with a range of computer operating systems and devices, helping to ensure that technological limitations were not a barrier to participation (Gray, 2004, p. 204). Online Surveys also supports interaction with built-in accessibility tools for major operating systems, meaning that participants were not excluded on the basis of accessibility considerations.

Although online surveys offer a cost-effective and efficient data collection tool, there are some limitations to the approach. The bounded structures of online surveys - and surveys more generally - mean that question phraseology has the potential to impact upon responses (Denscombe, 2014 , p. 181), and that there is little scope to test the extent to which responses reflect truthful reality (Newby, 2010). To prevent undue influence on participant responses, questions were designed to avoid leading respondents, ensuring that the richness of responses was represented and that potential researcher bias in questions could be mitigated.

The sampling of respondents followed a convenience sampling approach, using those participants 'who happen to be available and accessible at the time' (Cohen, Manion, \& Morrison, 2018, p. 218). The only stipulation was that participants had taught A-level music within the previous 2 years, ensuring that any perspectives were based upon current practice in relation to the revised specifications issued in 2016 (for the first examination in 2018). Although this approach does have limitations, especially regarding the extent to which the makeup of the research sample is representative of the teaching population at large, it is a common sampling approach in numerous research fields (Punch, 2009). The resultant research sample consisted of 72 respondents and engaged teachers from all 8 of the regions in England. Respondents worked in a range of institutional contexts (see Figure 1) with 50 of the 72 participants $(69.4 \%)$ working in a Head of Department role. As such, this survey captures the views of a significant sample that saw both geographical and institutional spread of respondents.

Respondents taught a total of 287 students, with a mean average class size of 4.2 students. However, the spread of these class sizes is particularly interesting, especially where groups exceed 10 students, as shown in Figure 2. Nine respondents recorded having class sizes greater than 10 students. A group size of three students was the modal response, consistent with the mean average size of A-level music groups (see Department for Education (2017)). Such small numbers are unlikely to be sustained in schools where finances are more challenging.

Thus, the contexts and class sizes for these respondents are broadly in line with the picture more nationally, making this a useful sample through which to explore teacher perceptions of A-level music.

\section{Survey results}

\section{Instrumental/vocal lessons}

Respondents were asked to report on the number of their students receiving instrumental or vocal lessons. Given the significant weighting of performance in A-level music qualifications, between 


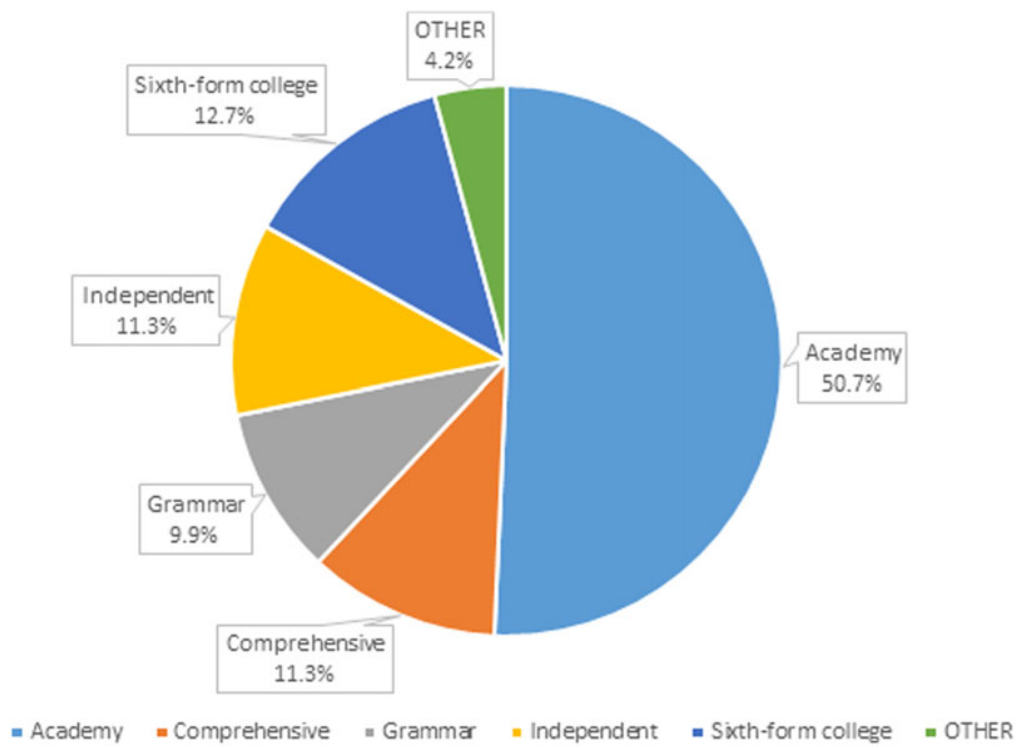

Figure 1. Institutional categories where respondents were employed.

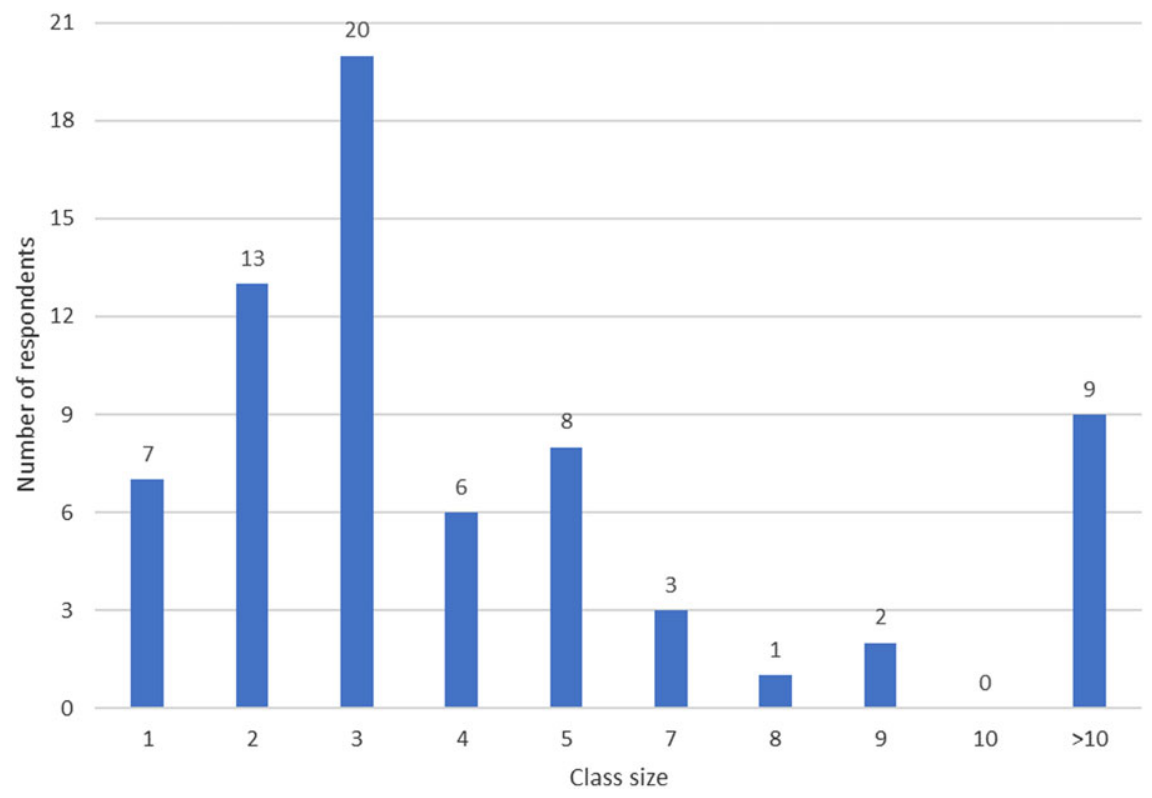

Figure 2. Frequency of class sizes reported in the survey.

$30 \%$ and $40 \%$ of the available marks (see Table 1), and the degree of specialised interest which A-level music supports, it is likely that most students will be engaged in advanced musical learning on an instrument or as a vocalist. Indeed, this may have been a constant factor in musical education. To understand the modalities and providers of instrumental lessons more precisely, respondents were asked to report on the numbers of their students engaged in instrumental or vocal lessons, and to state the number of these who were in receipt of lessons provided by the school, the local music education hub and by private music tutors. Respondents were able to count 


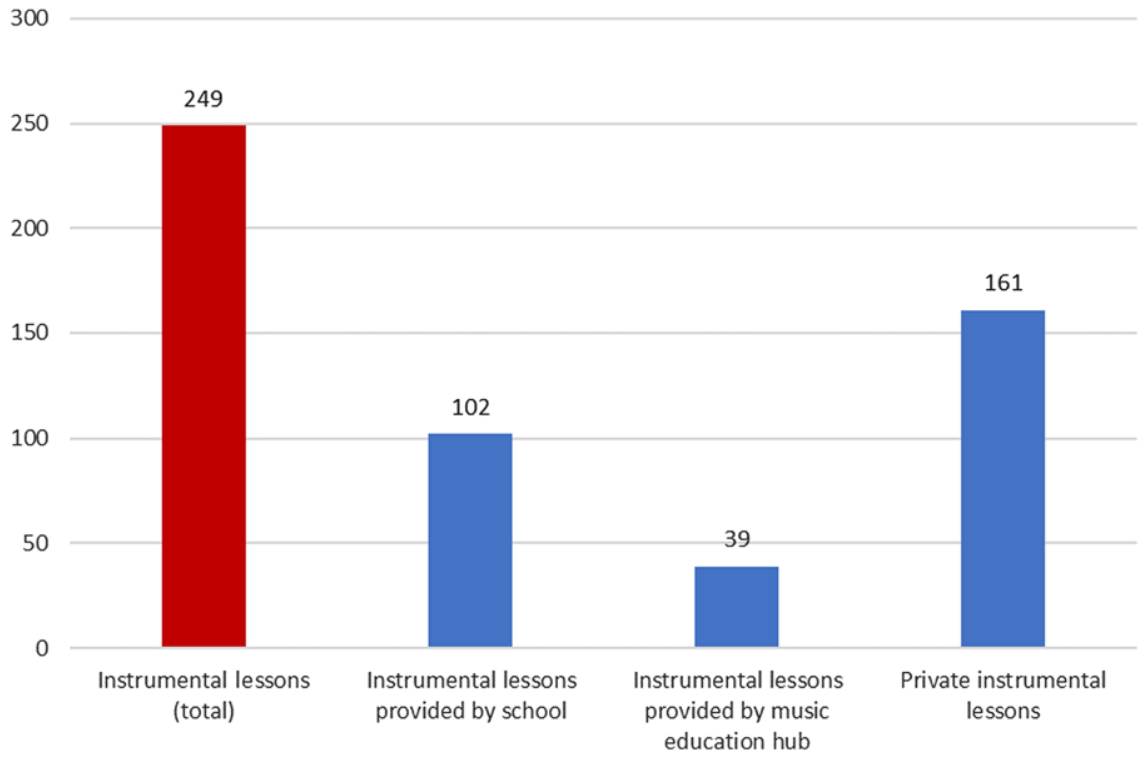

Figure 3. Instrumental lessons received by A-level music students divided into categories of provision.

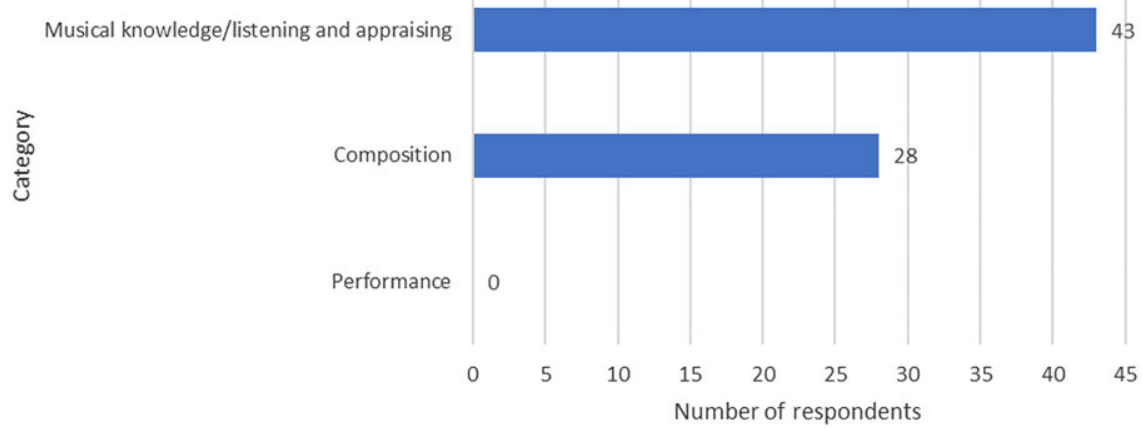

Figure 4. Responses to the question, 'Which of the three main areas do your students find most challenging about A-level music?'.

students in more than one category, as it was possible for students to be in receipt of lessons on more than one instrument in a different context. The resultant total if these categories are combined is therefore 302 , slightly higher than the 287 students described above, and inevitably includes some double counting. Figure 3, therefore, presents the total number of students in red (first column on the left), and the provider subdivisions in blue (three other columns).

These responses show that 249 students ( $86.7 \%$ of those pupils taught by survey respondents) are recorded as having instrumental lessons in addition to A-level music classes. A relatively small number of students received instrumental lessons from music education hubs for students represented by this sample, compared with much higher levels of instrumental lessons offered by private providers or schools themselves.

The impact of high numbers of instrumental lessons is shown in the overwhelming indication by respondents that performance components of A-level music were the least problematic for their students. Figure 4 shows that teachers identified the listening/appraising component to 
be the most challenging for their students. It is significant to note that there were no responses indicating performance to be the most difficult area of the qualification.

\section{A-level music as preparation for higher education transition}

Respondents were asked to record the number of students who had moved on from A-level music to continue their musical studies in higher education. Of the 287 students described in the survey, 144 continued to pursue musical study in higher education (Figure 5), meaning that around 50\% of the students from this sample use A-level music as a stepping stone towards higher musical study. ${ }^{1}$ These figures do not, of course, account for students who take alternative qualifications as a route to musical study as these fell outside of the scope of this study.

Teachers were asked to indicate whether they thought A-level music adequately prepared their students for the further study of music in conservatoire or university environments (Figure 6).

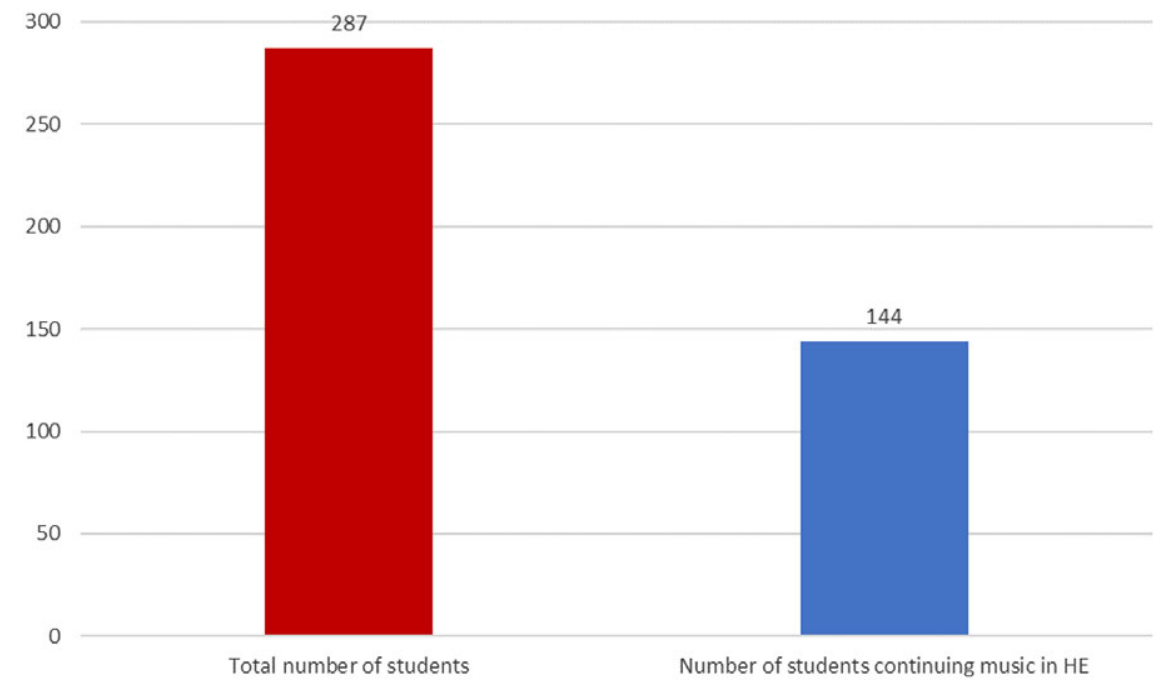

Figure 5. Number of students continuing to study music in HE settings.

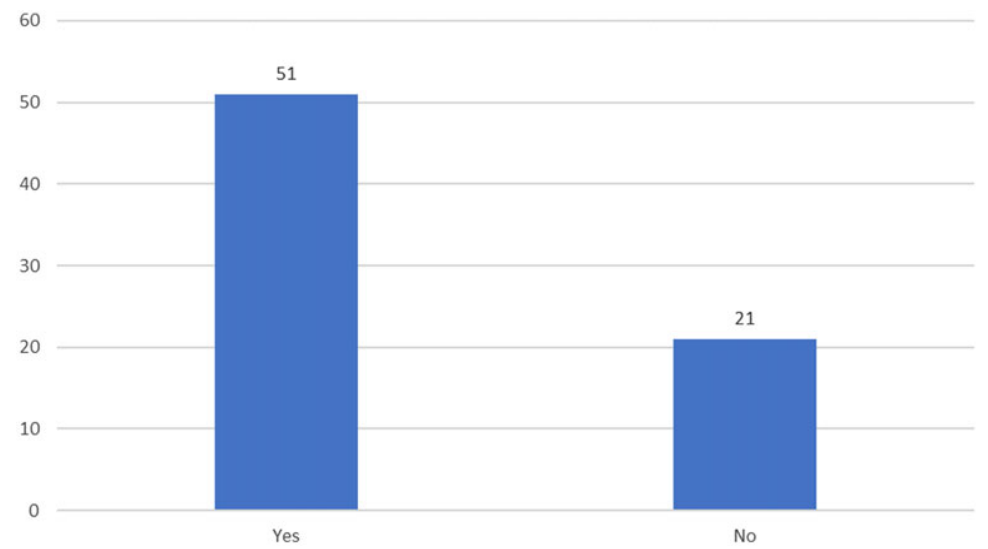

Figure 6. Responses to the question, 'Do you think A-level music adequately prepares your students for the further study of music, either in conservatoire or university environments?'. 
Responses were heavily skewed towards 'Yes' for this question, with $70.8 \%$ of respondents selecting this response.

Thus, most respondents indicated that A-level music was an adequate preparation for entry into further musical study in a HE context. Respondents identified the apparent breadth of skill coverage in A-level music to be an important feature, with specific mentions of performance, analysis, works, study and composition all featuring prominently in these responses. Other key words further emphasised the notions of subject depth and rigour as indicators of the ways in which A-level music prepares students for entry into higher education. The implications of these terms are explored more fully later in this article.

Although the majority of respondents answered 'Yes' to this question, there was a significant minority who selected 'No'. Coding of their clarifying comments highlights concerns around the appropriateness of current A-level provision as a stepping stone to higher music education. Key themes that emerge in these negative responses centre on the perceived exclusive nature of A-level music, in terms of the student body it caters for and the musical styles it prioritises, and a lack of choice for students.

\section{Musical relevance, subject coverage and real-world musical practices}

Respondents were asked whether their students perceived A-level music to be of relevance to their own musical interests. Despite many of the criticisms of A-level music lodged in other parts of the survey, the majority of respondents answered 'Yes' to this question, as shown in Figure 7.

Although 26 of the respondents selected 'No' (36.6\% of the 71 respondents) to this question, the majority, (63.4\%) felt that A-level music was relevant to the musical interests of their students. The fact that the majority of respondents did not feel that students perceive a complete disconnect between their own interests and those covered in A-level music is significant.

Respondents also identified the breadth of subject coverage as a positive feature in preparing students for entry into higher education (see Figure 8$)$. However, 47 respondents $(66.2 \%$ of the sample) also identified areas that they felt were omissions in the current specifications, and were asked to provide more details on these (see Table 2). In Figure 8 free-text responses have been grouped according to key themes to aid analysis and represent the range of views put forward in responses. Respondents were encouraged to identify multiple subject areas they felt should be included.

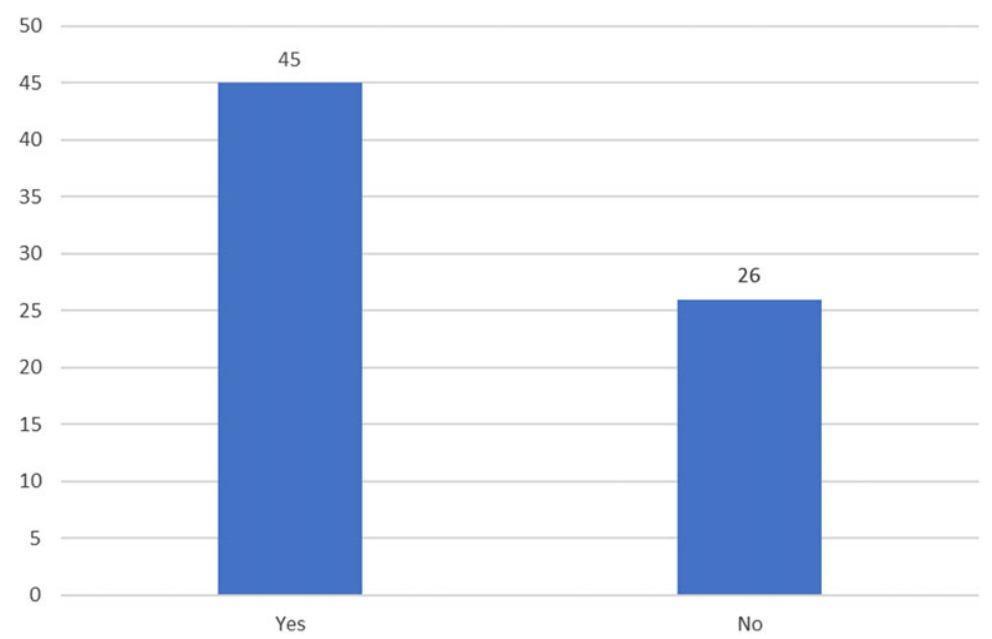

Figure 7. Responses to the question, 'Do you think students perceive A-level music as having relevance to their own musical interests?'. 


\section{Additional topic suggestions}

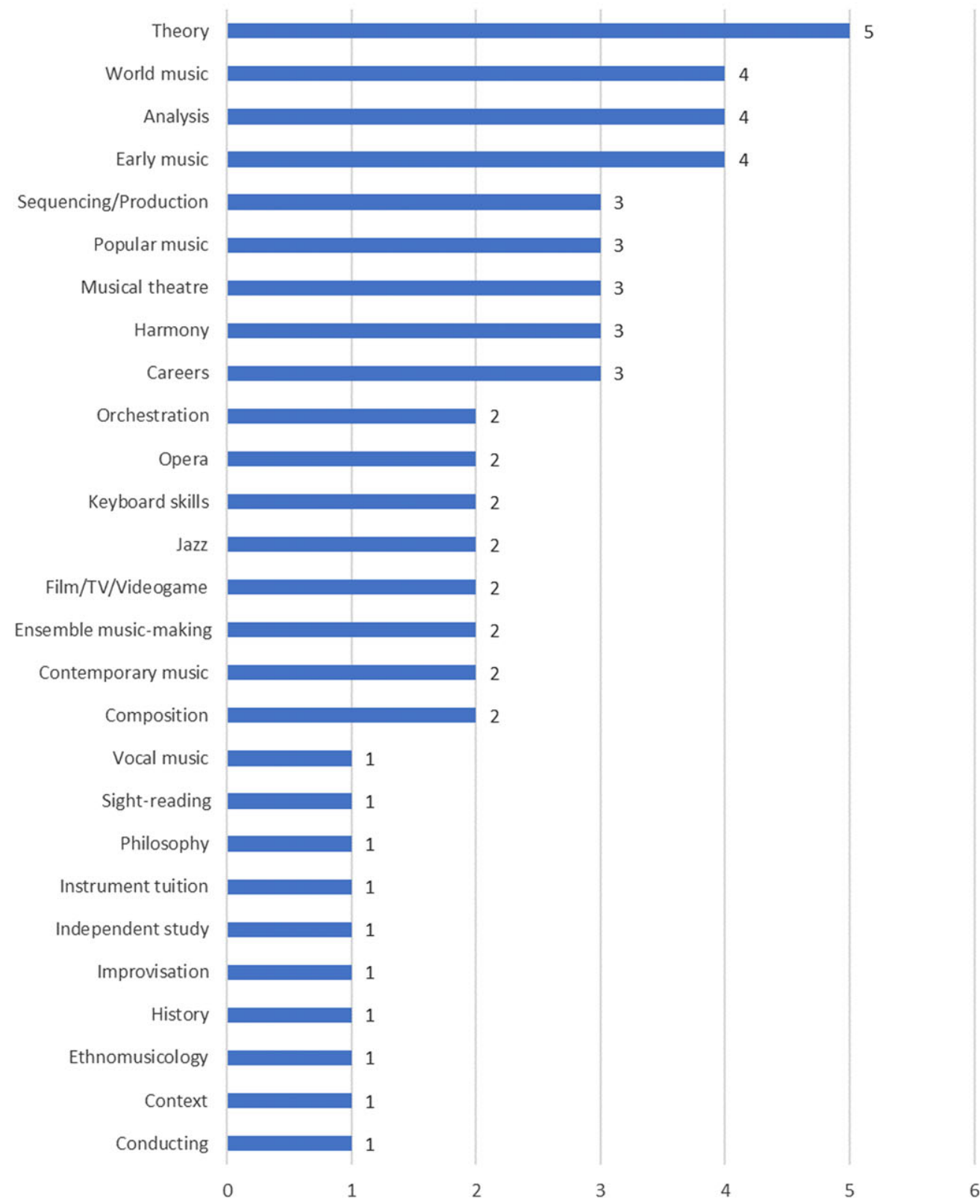

Figure 8. Free-text responses to the question 'Are there any topic areas that you feel A-level music should address, but does not?', arranged in descending order by the number of responses.

Of particular interest in Figure 8 are the indications of theory, world music and analysis as topics that A-level music does not currently address. This is significant as all three of these are ostensibly addressed under various areas of study across all current specifications (AQA, 2016; Edexcel, 2016; Eduqas, 2018; OCR, 2016), though several respondents were keen to stress that their selections were also motivated by a lack of time to cover these topics in sufficient detail. 
Table 2. Categorised Free-Text Responses to the Question 'Are there any topic areas that you feel A-level music should address, but does not?'

\begin{tabular}{|c|c|}
\hline Topic & Frequency \\
\hline Conducting & 1 \\
\hline Context & 1 \\
\hline Ethnomusicology & 1 \\
\hline History & 1 \\
\hline Improvisation & 1 \\
\hline Independent study & 1 \\
\hline Instrument tuition & 1 \\
\hline Philosophy & 1 \\
\hline Sight-reading & 1 \\
\hline Vocal music & 1 \\
\hline Composition & 2 \\
\hline Contemporary music & 2 \\
\hline Ensemble music-making & 2 \\
\hline Film/TV/Videogame & 2 \\
\hline Jazz & 2 \\
\hline Keyboard skills & 2 \\
\hline Opera & 2 \\
\hline Orchestration & 2 \\
\hline Careers & 3 \\
\hline Early music & 3 \\
\hline Harmony & 3 \\
\hline Musical theatre & 3 \\
\hline Popular music & 3 \\
\hline Sequencing/Production & 3 \\
\hline Analysis & 4 \\
\hline World music & 4 \\
\hline Theory & 5 \\
\hline
\end{tabular}

Three respondents also identified aspects of musical careers as an important area that is lacking from current A-level music qualifications:

'I don't know how it would fit in, but more on careers in music/music industry.'

'Conducting rehearsals. Planning events. Arranging music for groups. All things I do daily as a musician!'

'How to be a musician in today's world. How to gain employment in the industry. Selfpromotion. How to fill in a self-assessment tax return. How to put together a contract for a gig/show. Insurance. I could go on. My point is preparing them for the REAL world.' 
Opinions on the areas to be covered ranged from event management skills to arranging music for groups, and to filling out tax returns as a self-employed musician. The first of these acknowledges the time pressures associated with A-level qualifications, and identifies an aspect of musical life that extends beyond the usual remit of the classroom and foregrounds an important tension.

The second and third of these quotations note the importance of practical musicianship and personal management skills in developing a career as a musician. In particular, a focus on conducting/musical direction skills, taken broadly here to indicate taking leadership or direction of a musical scenario, is interesting given that such skills are not covered explicitly in the musical examinations most A-level candidates will have taken; performance activity is usually conceptualised as instrumental or vocal proficiency.

Other comments questioned the connections between A-level music and 'real' musical practice, with two respondents using this terminology in their responses:

\section{'Real composition!'}

'I liked the old AQA coursework that included an analytical comparison essay and stimulated composition. Much more true to real life and pragmatic.'

These examples evidence a tension between the apparent disconnect of composition assessments in A-level music, and the 'real-world' practices of composers working across many genres today. Similar findings are borne out in recent research on teacher perceptions of composition assessments at A-level (Devaney, 2018).

\section{Discussion}

\section{Instrumental lessons and performance components}

The data presented above outline a range of teacher perspectives on A-level music. Of particular interest here is the extent to which instrumental and vocal lessons play an important role for A-level music students, and the wider implications this has for access to this qualification, and the likelihood of success. The relatively high proportion of lessons provided by external providers compared with low numbers of Music Education Hub (MEH) lessons (Figure 3) reflects trends reported in the annual data return reports from these organisations. For a number of years, MEHs have reported relatively low levels of involvement in providing advanced lessons compared with their involvement in the early stages of musical learning (Fautley \& Whittaker, 2017, pp. 32-33). MEHs do, of course, continue to engage with advanced musicians, most likely through area-based ensembles, but only a few students seem to continue through to advanced lessons with a MEH. Thus, it seems that high levels of engagement with external providers, most likely individual instrumental teachers, is assumed as the norm for those pursuing A-level music, a large number of whom will go on to study music in a HE setting, or remain engaged in music-making as they move out of school. Although school lessons may be subsidised to an extent, private lessons are likely to come at a significant cost to parents, potentially widening the gap between school music and higher musical study.

For those unable to access such provision, due to reduced availability or restricted finances, the social justice implications for young musicians are potentially profound. Lack of access presents barriers to otherwise promising musical journeys, especially amongst those hailing from disadvantaged backgrounds. Given that $30 \%$ of A-level music marks are attributed to performance assessments, students who are not able to access this additional provision will be placed at a significant disadvantage. This is not the first time such a theme has been identified, with Moore (2014) gap between compulsory school music and university education becoming increasingly reliant on private instrumental education (p. 263). Indeed, none of the respondents to this survey identified the performance component as the most problematic for their students, pointing to a 
recognition, tacit or otherwise, that the training for this component principally takes place, in many cases, outside of the classroom. This finding confirms widely held assumptions that performance components of A-level music are supported by specialist tuition outside the music classroom, and it is a point of concern that despite multiple initiatives to widen access to musical education such a trend continues to be evident.

\section{Preparation for higher education}

For these respondents, A-level music was often a precursor to students continuing musical study in higher education, and acted as a useful preparatory tool for further study beyond school. Indeed, the majority of respondents felt that A-level adequately prepared their students for further study. The justifications for these views were divided into two key thematic areas: breadth and rigour. The breadth of subject matter (and skill areas) tested in A-level music has been outlined above. However, notions of rigour are particularly interesting here. In recent years, 'rigour' has become a highly politicised word in educational rhetoric (see, e.g., Gove, 2011, 2014; Morgan, 2015), bound up with notions of elitism, exclusion and hegemony, and linked to a focus on 'raising educational standards' (see, e.g., Gibb, 2018). In a political discourse on music education, this has become linked with notions of 'masterworks' and 'the great masters', almost always those of the Western Art Music canon. Such perspectives potentially reinforce inaccurate assumptions of the basis of many undergraduate music degrees (Heile, Stanley, \& Moreda, 2017).

The contentious status of Western European Art Music as the only compulsory area of study across all four examination boards, with other areas of study often being couched on similar terminology and concepts, has been explored in Whittaker (2018) and, from an historical perspective, in Legg (2012). The cultural associations of Western European Art Music, and its designation as the only compulsory area of study highlights a potential disconnect between the music that young people engage with outside of school, and that which constitutes school music (McPhail, 2013). This is somewhat analogous with notions of in-school and out-of-school composing identified in recent research into composing at KS4 and KS5 (Devaney, 2018). That said, many respondents noted the value of students engaging with unfamiliar repertoire and learning score-based analysis skills that can be taken forward into other musical areas, pointing towards notions of a vertical musical discourse and associated powerful knowledge (McPhail, 2017; Young \& Muller, 2013).

This is not without its problems. Respondents identified some of the ways in which expectations in these areas may be unrealistic for their students. In discussing the possible shortcomings in treatments of theory and analysis as A-level topics, some respondents felt that there were additional theoretical topics that should be covered, as well as some which were not covered in sufficient depth to support students in analytical activities or as preparation for further musical study. Wenden (2015) identified that some students in higher music education in New Zealand did not engage 'with the more theoretical aspects of their tertiary music degrees for reasons that are directly connected to their pre-tertiary educational experiences' (p. 16). Thus, the inclusion of such materials at A-level was clearly a key feature in preparatory work for higher musical education, but one that needs some careful attention in the coming years.

Indeed, the conceptualisation of music theory, and its associated fields, in this context is clearly underpinned by the continued apparent importance of western musical traditions to formal music qualifications in school contexts and, arguably, to teacher perceptions of advanced musical topics (Wright \& Davies, 2010). One respondent discussed this in more detail in relation to the theoretical language required to engage with harmony in A-level, noting that there was insufficient time to cover chordal basics, with one of their students being unable to read the bass clef. Such a response draws attention to significant challenges for both student and teacher as to how to begin to develop a deep knowledge of harmonic fundamentals in a limited timespan, and raises further questions about the extent to which expectations are realistic for those who have not necessarily 
been able to access music education outside of school. This view echoes that expressed in relation to performance skills. Indeed, both theory and analysis were topics that respondents felt were not addressed adequately in the current A-level provision. This also relates to a number of other responses, which expressed the opinion that A-level music in its current form has unrealistic expectations for the levels to be reached in a small amount of contact time. Again, this points to a widespread acceptance for students to be engaged in other forms of music tuition to support their A-level work, arguably to a greater extent than in similar subjects. Thus, it seems that A-level is part of a more complex landscape in terms of the preparations of young musicians for entry into higher musical education. We need to consider the extent to which these tacit assumptions are understood by policymakers and examination boards.

\section{Preparations for musical careers}

Throughout the survey, respondents were given multiple opportunities to comment on the subject coverage of A-level music. In most cases, the tripartite skill set assessed by the qualification was seen as a valuable asset, and one that distinguished its usefulness from graded music performance examinations, or other equivalent qualifications. By introducing the unfamiliar to students, there is of course the theoretical prospect of entering the area of the 'yet to be thought' in the 'discursive gap' (Bernstein, 2000, p. 30) created by being introduced to unfamiliar topics, sounds and musical cultures. Despite identifying a clear emphasis on Western European Art Music cultures, respondents reported that A-level music supported the exploration of the broader musical interests of their students. In a sense, this runs counter to narratives that school music education does not always respond to the musical interests of young people (Kinsella, Fautley, \& Whittaker, 2019) ${ }^{2}$. A school supporting A-level music is more likely to place value on the place of music in the school curriculum, and that this may, in fact, influence curriculum decision-making in earlier key stages (Bath et al., 2020, pp. 449-452).

When asked more specifically about the topics covered by the listening/appraising components of A-level music, respondents identified a number of subject areas which they felt were addressed insufficiently, and also raised important questions about the relationship between a school music qualification and 'real' musical practice. As Figure 4 showed earlier, this was the aspect that teachers felt was most challenging for students and is thus worthy of further investigation.

Although some courses of equivalent level contain elements of developing professional skills and competencies, A-levels are not traditionally associated with preparing students for entry into a particular industry, rather a field of knowledge and way of thinking about a subject. Survey respondents identified professional skills in support of a musical career such as music production, self-promotion, tax returns and event management, as being topics that were missing from A-levels. The numerous suggestions all fell under the broad category of 'musical career skills', skills which don't specifically underpin performance ability or musical knowledge, but play a key role in enabling a musician to share their musical skills with others and building their profile. As a point of comparison, A-levels in other creative and performing arts disciplines, such as Art and Design, Drama and Theatre, do not prescribe topics such as tax returns and event management, and yet these skills might be deemed equally important for freelance professionals working in this field ${ }^{3}$. An A-level in history is not expected to cover the professional skills required by freelance historians. Thus, whilst the present study does not wish to suggest that these skills should be side-lined in a young musician's development, we must ask whether there is a danger that Alevel music might be placed under too much strain to cover this too within the auspices of an academic qualification at Key Stage 5. The survey respondents identified fitting all the required study into the available timeframe to be a particular challenge, and this points to a key consideration for the sector going forward. Current policy discourse about 'knowledge-rich' teaching in schools, particularly in music education where learning to play a musical instrument is frequently conflated with music education, presents a stark challenge to this type of demand. 


\section{Conclusion}

The results of this survey raise important questions to be discussed across the music education sector. A-level music is under threat at a national level, with this being particularly acute in statefunded schools, and its continued existence is far from guaranteed. From these data, it is clear that this nationwide sample of teachers felt that A-level music offered something different from other existing performance and theoretical examinations, and that there were some key positive features of the qualification that supported preparations for higher musical study. Teachers generally welcomed the presence of analytical topics, composition and performance within the same qualifications framework. However, such a broad framework inevitably leads to disagreements over the balance struck between depth and coverage, and bring forward questions of curriculum coherence.

It is also clear that a high proportion of those taking A-level music go on to study music in higher education. Most of the respondents felt that A-level music adequately prepared their students for entry into higher musical education, but it is also clear that a significant minority felt that there were aspects that A-level music should address more fully to better prepare learners for further study. At present, it is clear that A-level music study is supported in oftenunacknowledged ways by instrumental lessons, many of which come at a cost. This study is not the first to identify such a finding, but points to the ongoing persistence of this issue in amplifying potential disparities in accessing higher musical education through the state sector alone. Understanding the implications of this is crucial if A-level music is to be sustained in a wide range of schools across the country. If we continue on the current trajectory, A-level music could well fall by the wayside even though it is viewed as a valuable qualification by many teachers.

\section{Notes}

1 As a point of comparison, there were 5,775 UCAS acceptances for higher education courses in history. A-level history had 51,438 entries in 2019 , meaning that around $11 \%$ of A-level history students went on to study the subject as undergraduate. 2 The media coverage in response to the Exchanging Notes Report, stylised as 'Stormzy vs. Mozart' highlights the stark polarity of viewpoints in the music which is 'relevant' and that which is educationally 'worthy'.

3 Applied A-level performing arts used to require students to speak with professional musicians about working in the music industry, but such qualifications were withdrawn in 2017 (Edexcel, 2008). https://qualifications.pearson.com/en/ qualifications/edexcel-a-levels/performing-arts-2008.html.

\section{References}

AQA. (2016). A-LEVEL MUSIC (7272) Specification For teaching from September 2016 onwards. AQA.

ASSOCIATION OF SCHOOL AND COLLEGE LEADERS. (2018). Funding Crisis puts A level music and languages in peril

[Press release]. www.ascl.org/news-and-views/news_news-detail.funding-crisis-puts-a-level-music-and-languages-in-peril. html

BATH, N., DAUBNEY, A., MACKRILL, D. \& SPRUCE, G. (2020). The declining place of music education in schools in England. Children \& Society, 34, 443-457. doi: 10.1111/chso.12386

BERNSTEIN, B. (2000). Pedagogy, Symbolic Control and Identity: Theory, Research, Critique (rev. ed.). New York: Rowman \& Littlefield.

COHEN, L., MANION, L. \& MORRISON, K. (2018). Research Methods in Education (8th ed.). London: Routledge.

CRESSWELL, J. W. (2009). Research Design: Qualitative, Quantitative, and Mixed Methods Approaches (3rd ed.). Thousand Oaks, California: Sage.

CULTURAL LEARNING ALLIANCE. (2017). What is the EBacc? https://culturallearningalliance.org.uk/briefings/what-isthe-ebaccl

DAUBNEY, A. \& MACKRILL, D. (2017). Changes in Secondary Music Curriculum Provision Over Time: 2012-16. https:// www.ism.org/images/files/Changes-in-Secondary-Music-Curriculum-Provision-Over-Time-Music-Mark-Conference.pdf

DAUBNEY, A., SPRUCE, G. \& ANNETTS, D. (2019). Music Education: State of the Nation. London.

DENSCOMBE, M. (2010). The Good Research Guide for Small-Scale Social Research Projects (4th ed.). London: Open University Press.

DENSCOMBE, M. (2014). The Good Research Guide for Small-Scale Social Research Projects (5th ed.). Maidenhead: McGrawHill Education. 
DEPARTMENT FOR EDUCATION. (2017). Find and compare schools in England. https://www.compare-schoolperformance.service.gov.uk/download-data

DEPARTMENT FOR EDUCATION. (2019). Find and compare schools in England (2018/19). https://www.compare-schoolperformance.service.gov.uk/download-data

DEVANEY, K. (2018). How Composing Assessment in English Secondary Examinations Affects Teaching and Learning Practices. (PhD). Birmingham: Birmingham City University.

EDEXCEL. (2008). Edexcel Applied A level Performing Arts (2008). Edexcel.

EDEXCEL. (2016). A Level Music Specification: Pearson Edexcel Level 3 Advanced GCE in Music (9MU0). Edexcel.

EDUQAS. (2018). WJEC Eduqas GCE A LEVEL in MUSIC (2nd ed.). Eduqas.

FAUTLEY, M. \& WHITTAKER, A. (2017). Key Data on Music Education Hubs 2016. Arts Council England website: http:// www.artscouncil.org.uk/children-and-young-people/music-education-hubs-survey

FAUTLEY, M. \& WHITTAKER, A. (2018). Key Data on Music Education Hubs 2017. Arts Council England website: http:// www.artscouncil.org.uk/children-and-young-people/music-education-hubs-survey

GIBB, N. (2018). Nick Gibb: Teachers are taking control of their profession. In Speech Given at the Festival of Education. Online: Department for Education.

GOVE, M. (2011). The Need to Reform the Education System. University of Cambridge. https://www.gov.uk/government/ speeches/michael-gove-to-cambridge-university

GOVE, M. (2014). Michael Gove speaks about securing our children's future. London Academy of Excellence. Speech: https:// www.gov.uk/government/speeches/michael-gove-speaks-about-securing-our-childrens-future

GRAY, D. E. (2004). Doing Research in the Real World (3rd ed.). London: Sage.

HEILE, B., STANLEY, J. \& MOREDA, E. R. (eds.). (2017). Higher Music Education in the Twenty-First Century. London: Routledge.

INCORPORATED SOCIETY OF MUSICIANS. (2020). ISM | Bacc for the Future Campaign. https://www.baccforthefuture. $\mathrm{com} /$

JEFFREYS, B. (2018). Creative subjects being squeezed, schools tell BBC. http://www.bbc.co.uk/news/education-42862996

KERNOHAN, D. (2020). Principal Subject - POLAR - David Kernohan. https://public.tableau.com/profile/david.kernohan\#!/ vizhome/Principalsubject-POLAR/Sheet1

KINSELLA, V., FAUTLEY, M. \& WHITTAKER, A. (2019). Exchanging Notes: Research Summary Report. https://www. youthmusic.org.uk/file/4697/download?token=MhB_6n95

LEGG, R. (2012). Bach, Beethoven, Bourdieu: 'Cultural capital' and the scholastic canon in England's A-level examinations. The Curriculum Journal, 23(2), 157-172.

MCPHAIL, G. (2013). The canon or the kids: Teachers and the recontextualisation of classical and popular music in the secondary school curriculum. Research Studies in Music Education, 35(1), 7-20.

MCPHAIL, G. (2017). Powerful knowledge: Insights from music's case. The Curriculum Journal, 28(4), 524-538.

MOORE, G. (2014). Mind the gap: Privileging epistemic access to knowledge in the transition from Leaving Certificate music to higher education. Irish Educational Studies, 33(3), 249-268. doi: 10.1080/03323315.2014.926165

MORGAN, N. (2015). Why Knowledge Matters. Carlton Club. https://www.gov.uk/government/speeches/michael-gove-tocambridge-university

NEWBY, P. (2010). Research Methods for Education. London: Pearson.

OCR. (2016). A LEVEL Specification MUSIC H543 For first assessment in 2018. OCR.

OFQUAL. (2015). GCE Subject Level Conditions and Requirements for Music. (Ofqual/15/5635). Ofqual: https://www.gov.uk/ government/uploads/system/uploads/attachment_data/file/413314/gce-subject-level-conditions-for-music.pdf.

PUNCH, K. (2009). Introduction to Research Methods in Education. London: Sage.

SAVAGE, J. \& BARNARD, D. (2019). The State of Play: A Review of Music Education in England 2019. https://www. musiciansunion.org.uk/StateOfPlay.aspx

WENDEN, L. (2015). Talking about Transition: An Exploration of Secondary to Tertiary Transition Process for Music Students in a New Zealand Context. (Masters). Wellington: Victoria University.

WHITTAKER, A. (2018). Investigating the canon in A-Level music: Musical Prescription in A-Level Music Syllabuses (for first examination in 2018). British Journal of Music Education.

WHITTAKER, A., FAUTLEY, M., KINSELLA, V. \& ANDERSON, A. (2019). Geographical and social demographic trends of A-level music students. http://researchonline.rcm.ac.uk/502/

WRIGHT, R. \& DAVIES, B. (2010). Class, power, culture and the music curriculum. In R. Wright (ed.), Sociology and Music Education (pp. 35-50). Farnham: Ashgate.

YOUNG, M. \& MULLER, J. (2013). On the powers of powerful knowledge. Review of Education, 1(3), 229-250.

Cite this article: Whittaker A (2021). Teacher perceptions of A-level music: tension, dilemmas and decline. British Journal of Music Education 38, 145-159. https://doi.org/10.1017/S0265051720000352 